\title{
High-Yield One-Pot Recovery and Characterization of Nanostructured Cobalt Oxalate from Spent Lithium-Ion Batteries and Successive Re-Synthesis of $\mathrm{LiCoO}_{2}$
}

\author{
Young Min Park ${ }^{1}$ (D), Hana $\operatorname{Lim}^{1}$ [D , Ji-Hoon Moon ${ }^{1,2}{ }^{,}$Ho-Nyun Lee ${ }^{1}$, Seong Ho Son ${ }^{1}$, \\ Hansung Kim ${ }^{2, *}$ and Hyun-Jong Kim ${ }^{1, *}$ \\ 1 Surface Technology Group, Korea Institute of Industrial Technology (KITECH), Incheon 21999, Korea; \\ youngmin@kitech.re.kr (Y.M.P.); hana0313@kitech.re.kr (H.L.); jhmoon37@gmail.com (J.-H.M.); \\ hnlee@kitech.re.kr (H.-N.L.); shson@kitech.re.kr (S.H.S.) \\ 2 Department of Chemical and Biomolecular Engineering, Yonsei University, Seoul 03722, Korea \\ * Correspondence: elchem@yonsei.ac.kr (H.K.); hjkim23@kitech.re.kr (H.-J.K.); Tel.: +82-32-850-0248 (H.-J.K.); \\ Fax: +82-32-850-0230 (H.-J.K.)
}

Received: 11 July 2017; Accepted: 2 August 2017; Published: 7 August 2017

\begin{abstract}
A complete recycling process for the cathode material of spent lithium-ion batteries is demonstrated with a simple two-step process comprised of one-pot cobalt recovery to nanostructured materials and single step synthesis of $\mathrm{LiCoO}_{2}$. For the facile and efficient recovery of cobalt, we employ malic acid as a leaching agent and oxalic acid as a precipitating agent, resulting in nanostructured cobalt oxalate. X-ray diffraction and Fourier transform infrared spectroscopy (FT-IR) analysis clearly show that cobalt species are simultaneously leached and precipitated as cobalt oxalate with a high yield of $99.28 \%$, and this material can then be used as a reactant for the synthesis of $\mathrm{LiCoO}_{2}$ for use as a cathode material. In addition to its advantages in simplifying the process, the proposed method allows for not only enhancing the efficiency of cobalt recovery, but also enabling reaction without a reducing agent, $\mathrm{H}_{2} \mathrm{O}_{2}$. Through successive single-step reaction of the obtained cobalt oxalate without any purification process, $\mathrm{LiCoO}_{2}$ is also successfully synthesized. The effect of the annealing temperature during synthesis on the nanostructure and charge-discharge properties is also investigated. Half-cell tests with recycled $\mathrm{LiCoO}_{2}$ exhibit a high discharge capacity $\left(131 \mathrm{~mA} \cdot \mathrm{h} \cdot \mathrm{g}^{-1}\right)$ and $93 \%$ charge-discharge efficiency.
\end{abstract}

Keywords: cobalt recovery; nanostructured cobalt oxalate; spent Li-ion batteries; one-pot process; lithium cobalt oxide

\section{Introduction}

Lithium-ion batteries (LIBs) have been considered the best technology for sustainable transport and smart electronics due to their excellent properties, including high energy density, long storage life, low self-discharge efficiency, and a wide operating temperature [1-3]. They are now extensively used as power sources in various portable electronic devices (e.g., smart phones), and their potential applications are also expanding to electric vehicles (EVs) and hybrid EVs (HEVs) [4,5]. However, LIBs in most portable devices have a lifespan of less than 3 years, and those in HEVs and EVs are projected to have a lifespan of roughly 10 years [4,6]. Given these limited lifespans and increasing production, it must be noted that equal amounts of spent LIBs are produced after they have reached the end of their useful life. Although spent LIBs are generally not classified as hazardous waste, their inappropriate disposal may cause environmental pollution because of the presence of toxic compounds. From an economic perspective, high-value nonferrous metals such as cobalt and nickel 
are contained in the positive electrode (cathode) [7-9]. In the cathode of spent LIBs, the concentration of metallic ingredients has been reported to be in the following order: cobalt $(5-20 \%)>$ nickel $(5-10 \%)$ $>$ lithium (5-7\%) [10], because the available cathode materials are mostly used in a form of $\mathrm{LiCoO}_{2}$ and some alternatives such as $\mathrm{LiNi}_{0.33} \mathrm{Mn}_{0.33} \mathrm{Co}_{0.33} \mathrm{O}_{2}, \mathrm{LiNi}_{0.8} \mathrm{Co}_{0.15} \mathrm{Al}_{0.05} \mathrm{O}_{2}$, and $\mathrm{LiFePO}_{4}$. Among these components, the recovery of cobalt is the most economically feasible since cobalt is about twice as expensive as nickel and 15 times more expensive than copper [11]. Furthermore, cobalt is classified as carcinogenic, mutagenic, and toxic to human health. Therefore, the recovery of cobalt from spent LIBs is required in order to prevent environmental pollution from spent LIBs as well as keep pace with the expansion of LIBs' use in various applications [9].

Until now, several approaches have been developed to recover the cobalt species from spent LIBs, including pyrometallurgical [12,13], biometallurgical [14,15], electrochemical [16-18], and hydrometallurgical methods [10,19-22]. Among them, hydrometallurgical processes are most widely used for the complete recovery of metals with high purity and low energy consumption. They mainly involve acid leaching, chemical precipitation, separation, and electrochemical recovery [10]. In the leaching step, strong inorganic acids such as $\mathrm{H}_{2} \mathrm{SO}_{4}, \mathrm{HCl}$, and $\mathrm{HNO}_{3}$ have conventionally been used as leaching agents, with a high extraction efficiency of cobalt. Inorganic leaching agents release toxic gases like $\mathrm{SO}_{3}, \mathrm{Cl}_{2}$, and $\mathrm{NO}_{x}$, and the waste acidic solution causes serious secondary damage to the environment and human health. Moreover, the recovery processes are still complicated due to the multiple steps required, including the separation and purification processes of cobalt and other components.

Thus, various organic acids have been extensively studied as environmentally benign leaching agents due to their favorable properties, including ease of degradation, recyclability, absence of toxic gases, and the avoidance of secondary pollution. For example, Li et al. reported that citric acid, ascorbic acid, and malic acid could be successfully used for cobalt recovery from the cathode materials of spent LIBs $[19,21,23]$. However, the leaching efficiencies of the organic acids were significantly lower than those of sulfuric acid, even with the addition of sufficient hydrogen peroxide, which leads to a more facile separation and purification process for commercialization [24]. Therefore, a simple and environmentally acceptable process is urgently required to avoid adverse environmental impact and the mechanical complexity of the battery recycling process.

In this study, a novel one-pot recovery process was designed using malic acid and oxalic acid as a leaching agent and a precipitator, respectively, which is more efficient than the previous process wherein the leaching process was separated from precipitation. The cobalt species were efficiently leached and simultaneously precipitated by an aqueous mixture of malic acid and oxalic acid in a single process. It was also found that our process could be successfully operated without the assistance of a reducing agent via Le Chatelier's principle. In addition, the precipitated cobalt oxalate compound was used to prepare the cathode material of $\mathrm{LIBs} \mathrm{LiCoO}_{2}$, in a single-step reaction without purification process.

Therefore, our novel process successfully demonstrated a complete recycling process of the cathode material of spent LIBs in a two-step process composed of one-pot cobalt recovery and single-step synthesis of $\mathrm{LiCoO}_{2}$. This is considered to simplify the Co recovery process compared to previous recovery processes of spent LIBs that are composed of multiple steps such as leaching, chemical precipitation, solvent extraction, and synthesis of cathode material.

\section{Experimental}

\subsection{Screening of Organic Acids}

The cathode material was separated from spent LIBs for cellphones, and was kindly supplied by Sungeel HiTech Co. Ltd. (Incheon, Korea). Before the leaching experiments, the cathode material was thermally calcined at $700{ }^{\circ} \mathrm{C}$ to remove organic impurities. For the selection of an environmentally-benign leaching agent, various organic acids were used without further purification. 
Leaching experiments were conducted in a $0.5 \mathrm{~L}$ three-necked round-bottomed thermostatic Pyrex reactor equipped with a temperature control facility, reflux condenser, and a mechanical impeller. A measured amount of the cathode material was added to a $2 \mathrm{M}$ aqueous acid and $5 \mathrm{wt} \% \mathrm{H}_{2} \mathrm{O}_{2}$ solution with a solid/liquid ratio of $1 / 10$. The system was maintained at $80^{\circ} \mathrm{C}$ under constant magnetic agitation of $300 \mathrm{rpm}$ for $3 \mathrm{~h}$. Leach liquor samples of $5 \mathrm{~mL}$ were periodically drawn at desired time intervals. After filtering the samples, the metal ion concentration in the solution was analyzed by inductively coupled plasma atomic emission spectroscopy.

\subsection{One-Pot Process}

An aqueous mixture of malic acid and oxalic acid was used as leaching and precipitation agent, respectively, for the demonstration of simultaneous leaching and precipitation in a single reactor. The total concentration of acids was fixed at $2 \mathrm{M}$, and the molar ratio of malic acid to oxalic acid was 1 to 1 . The precipitated cobalt oxalate was filtered and washed with distilled water. The phase purity and chemical structure of cobalt oxalate was characterized by X-ray diffraction (XRD, Rigaku, Tokyo, Japan) and Fourier transform infrared spectroscopic (FT-IR, Shimadzu, Kyoto, Japan) analysis.

\subsection{Synthesis of $\mathrm{LiCoO}_{2}$ Powder}

To explore a one-step process for the synthesis of $\mathrm{LiCoO}_{2}$ powder, the cobalt oxalate obtained from the one-pot process was mixed with a lithium precursor $\left(\mathrm{Li}_{2} \mathrm{CO}_{3}\right.$ or $\left.\mathrm{LiOH}\right)$ in a mortar with a $\mathrm{Li} / \mathrm{Co}$ ratio of $1.05 / 1$. Subsequently, the mixtures were calcined in a muffle furnace at different temperatures from $400{ }^{\circ} \mathrm{C}$ to $900^{\circ} \mathrm{C}$ for $8 \mathrm{~h}$. The products were thoroughly washed with distilled water and dried at $80^{\circ} \mathrm{C}$ for $24 \mathrm{~h}$. The morphology of the synthesized $\mathrm{LiCoO}_{2}$ powder was characterized by field emission scanning electron microscopy (FE-SEM, Thermo Fisher Scientific, Waltham, MA, USA) and XRD.

\subsection{Electrochemical Measurements}

Cyclic voltammetry and galvanostatic charge-discharge experiments were conducted on individual electrodes in a typical three-electrode cell with $1 \mathrm{M} \mathrm{Li}_{2} \mathrm{SO}_{4}$ aqueous solution. A platinum wire and a saturated calomel electrode (SCE) were used as the counter and reference electrodes, respectively. A Luggin capillary faced the working electrode at a distance of $5 \mathrm{~mm}$. The working electrodes were prepared by mixing active material, acetylene black, and poly (tetrafluoroethylene) (PTFE) in a weight ratio of 85:10:5, and pressing the powdered mixture onto a titanium mesh.

\section{Results and Discussion}

\subsection{Screening Test of Organic Acids}

A systematic screening procedure for various organic acids was performed based on leaching efficiency. Considering the chemical structure and reaction constant, eight candidate leaching agents from malic acid to acrylic acid were tested, as shown in Figure 1. The results showed that sulfuric acid, citric acid, and malic acid exhibited higher leaching efficiency compared with the other six organic acids, at $95.8 \%, 89.9 \%$, and $86.69 \%$, respectively. The carboxyl and hydroxyl groups in citric and malic acid are expected to give rise to $\mathrm{H}^{+}$in distilled water [23,24]; therefore, dissociated carboxyl groups will react with cobalt ions upon the addition of the reducing agent $\mathrm{H}_{2} \mathrm{O}_{2}$, the ability of which to enhance the aqueous solubility of cobalt ions is also well known [22,25]. Among these organic acids, malic acid was chosen in this study for further investigation of a one-pot leaching and precipitation process to re-synthesize $\mathrm{LiCoO}_{2}$, thanks to its advantages in price and accessibility over citric acid.

A schematic view of the one-pot process proposed here is given in Figure 2. With the addition of oxalic acid into a solution with malic acid, cobalt ions are expected to simultaneously undergo a leaching and precipitation process, resulting in cobalt oxalate. Oxalic acid is a common weak acid, and it is well-known that its anion acts as an excellent ligand to easily form coordination compounds 
with metal ions thanks to its dibasic characteristics $[10,26]$. Figure 3 shows the optical image, scanning electron microscopy (SEM) image, and XRD pattern of the precipitated powder from the one-pot process. They clearly indicate that cobalt oxalate forms during the one-pot process and grows to a rod-like shape with a (001) direction that is attributed to hydrogen bonding during the reaction, as previously reported $[27,28]$. FT-IR analysis also shows several peaks corresponding to hydrated metal oxalates (Figure 4). The broad band at $3360 \mathrm{~cm}^{-1}$ is attributed to the water of hydration. The band at $1622 \mathrm{~cm}^{-1}$ corresponding to asymmetric $v(\mathrm{C}-\mathrm{O})$ and the closely spaced bands at $1362 \mathrm{~cm}^{-1}$ and $1317 \mathrm{~cm}^{-1}$ assigned to symmetric $v(\mathrm{C}-\mathrm{O})$, respectively, clearly reveal the presence of bridging oxalates, with all four oxygen atoms coordinated to the cobalt atoms.

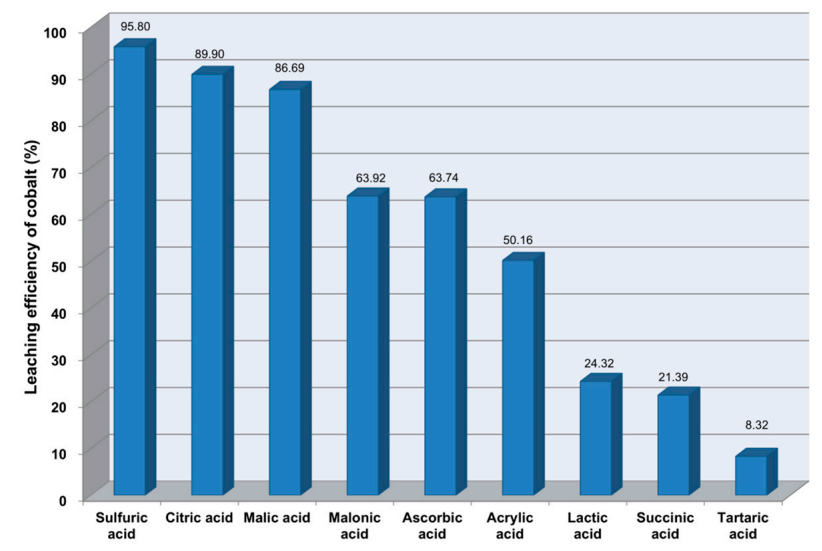

Figure 1. Cobalt leaching efficiency comparison from spent batteries for each leaching agent used in this study.

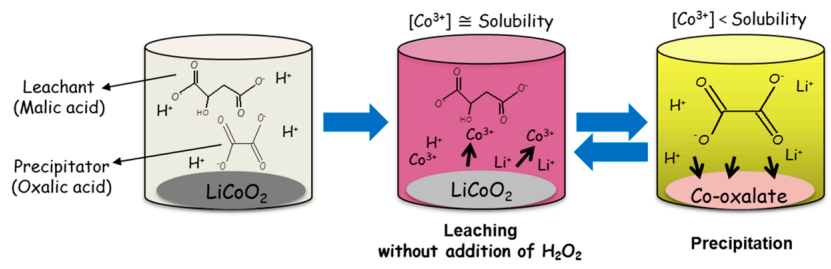

Figure 2. A schematic view of the one-pot process used to obtain cobalt species in the form of Co-oxalate from spent Li batteries using malic acid and oxalic acid.
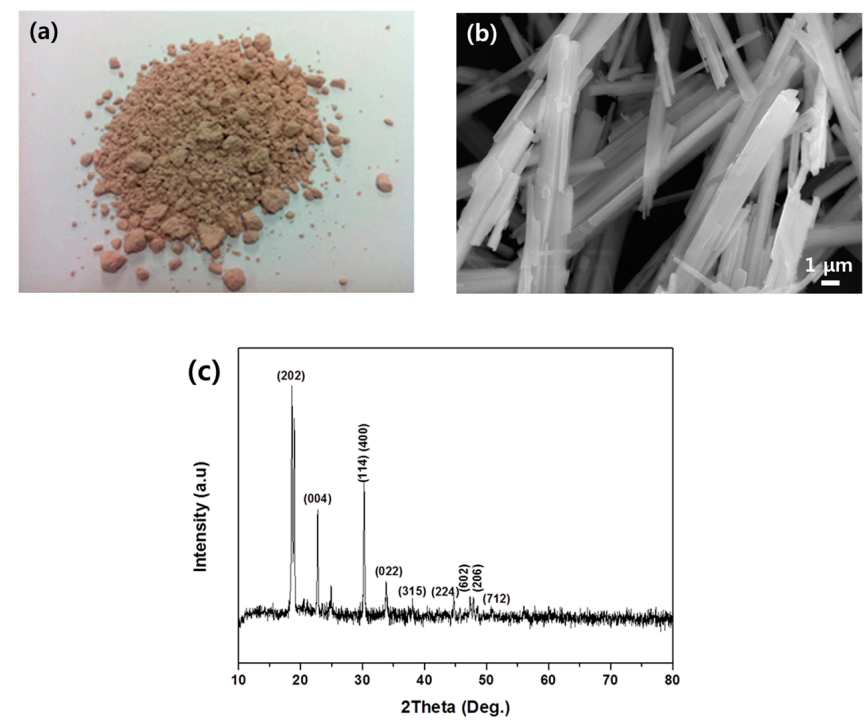

Figure 3. (a) Optical image; (b) SEM image of precipitated Co-oxalate; (c) powder XRD pattern. 


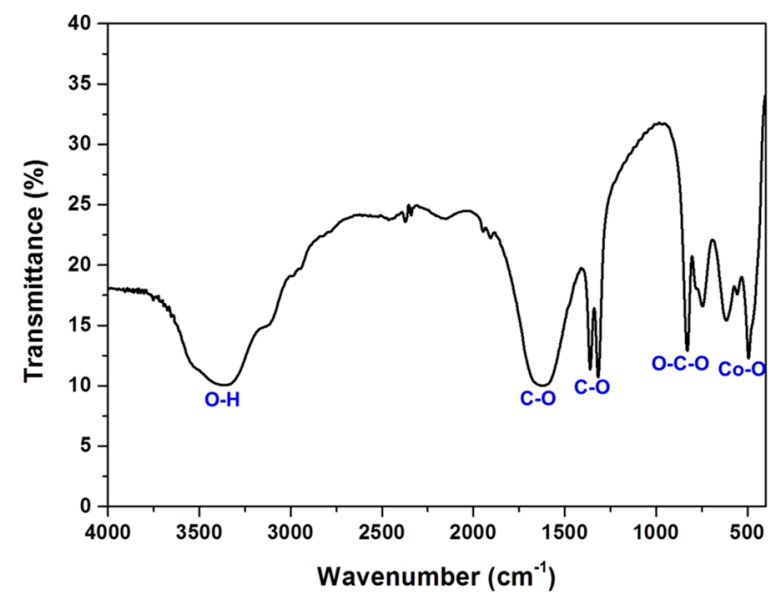

Figure 4. Fourier transform infrared (FT-IR) spectrum of the Co compound resulting from our process.

Furthermore, oxalic acid allows for a process that does not employ $\mathrm{H}_{2} \mathrm{O}_{2}$ as a reduction agent, without any loss of recovery efficiency (Figure 5). Previously, hydrometallurgical processes for recycling cobalt from spent lithium-ion battery have included the addition of $\mathrm{H}_{2} \mathrm{O}_{2}$. The presence of $\mathrm{H}_{2} \mathrm{O}_{2}$ significantly favors the leaching of cobalt, since $\mathrm{H}_{2} \mathrm{O}_{2}$ can reduce the $\mathrm{Co}^{3+}$ to $\mathrm{Co}^{2+}$ which is more readily dissolved than $\mathrm{Co}^{3+}$ in malic acid $\left(\mathrm{C}_{4} \mathrm{H}_{6} \mathrm{O}_{5}\right)$ solution as described in Equation (1). In the absence of $\mathrm{H}_{2} \mathrm{O}_{2}$, the leaching efficiency of cobalt reached only $40 \%$, as shown in Figure 5 . In our one-pot process, however, the released $\mathrm{Co}^{3+}$ from the spent cathode materials immediately react with oxalic acid $\left(\mathrm{C}_{2} \mathrm{H}_{2} \mathrm{O}_{4}\right)$ to form a cobalt oxalate precipitate; in other words, aqueous cobalt ions are removed from the solution (Equation (2)). Hence, the removal of $\mathrm{Co}^{3+}$ ions shifts the chemical equilibrium to facilitate the dissolution of $\mathrm{Co}^{3+}$ ions by Le Chatelier's principle, as shown in Figure 2.

$$
\begin{aligned}
& 2 \mathrm{LiCoO}_{2} \text { (s) }+3 \mathrm{C}_{4} \mathrm{H}_{6} \mathrm{O}_{5} \text { (aq.) }+\mathrm{H}_{2} \mathrm{O}_{2} \rightarrow 2 \mathrm{Co}^{2+} \text { (aq.) }+2 \mathrm{Li}^{+}+3 \mathrm{C}_{4} \mathrm{H}_{4} \mathrm{O}_{5}{ }^{2-} \text { (aq.) }+4 \mathrm{H}_{2} \mathrm{O}+\mathrm{O}_{2} \text { (g) } \\
& 2 \mathrm{LiCoO}_{2} \text { (s) }+\mathrm{C}_{4} \mathrm{H}_{6} \mathrm{O}_{5} \text { (aq.) }+2 \mathrm{C}_{2} \mathrm{H}_{2} \mathrm{O}_{4} \text { (aq.) } \rightarrow 2 \mathrm{CoC}_{2} \mathrm{O}_{4} \text { (s) } \downarrow+2 \mathrm{Li}^{+}+\mathrm{C}_{4} \mathrm{H}_{4} \mathrm{O}_{5}{ }^{2-} \text { (aq.) }+2 \mathrm{H}_{2} \mathrm{O}
\end{aligned}
$$

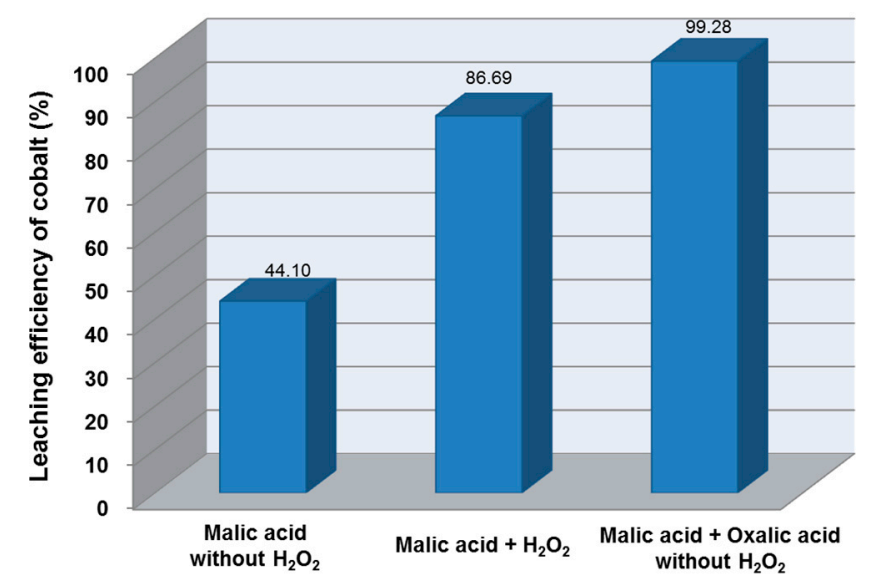

Figure 5. Cobalt leaching efficiency of malic acid with $\mathrm{H}_{2} \mathrm{O}_{2}$ or oxalic acid.

Consequently, our one-pot process eliminates the need for the reduction agent $\mathrm{H}_{2} \mathrm{O}_{2}$ to reduce the poorly soluble $\mathrm{Co}^{3+}$ to the highly soluble $\mathrm{Co}^{2+}$. The cobalt recovery efficiency in our process is enhanced to $99.28 \%$ compared with the processes using only oxalic acid or malic acid $/ \mathrm{H}_{2} \mathrm{O}_{2}$, which have recovery efficiencies of $44.10 \%$ and $86.69 \%$, respectively. Therefore, an efficient one-pot process to acquire Co species was achieved, whereas the leaching and precipitation processes are separated in the other conventional method. 


\subsection{Synthesis of $\mathrm{LiCoO}_{2}$ Powder from Co-Oxalate}

To re-synthesize $\mathrm{LiCoO}_{2}$ from the obtained $\mathrm{Co}$-oxalate, $\mathrm{LiOH}$ and $\mathrm{Li}_{2} \mathrm{CO}_{3}$ were added as lithium precursors, and the mixture was calcined from $400{ }^{\circ} \mathrm{C}$ to $900{ }^{\circ} \mathrm{C}$. XRD shows that $\mathrm{LiCoO}_{2}$ is synthesized with the crystal structure of the layered $\alpha-\mathrm{NaFeO}_{2}$-type structure in the $\mathrm{R} 3 \mathrm{~m}$ space group from Co-oxalate after calcination (Figure 6) $[29,30]$. The calcination process is known to induce thermal decomposition as well as dehydration of Co-oxalate, thus removing carbon and other residual species $[27,28]$. Note that while the peak corresponding to $\mathrm{Co}_{3} \mathrm{O}_{4}$ also appears in the sample from reaction with $\mathrm{Li}_{2} \mathrm{CO}_{3}$, only the crystalline planes of the $\mathrm{LiCoO}_{2}$ peaks are indexed after reaction with $\mathrm{LiOH}$. It is expected that the high melting point of $\mathrm{Li}_{2} \mathrm{CO}_{3}$ and oxygen-rich environment facilitates the oxidation of $\mathrm{Co}$, hence producing $\mathrm{Co}_{3} \mathrm{O}_{4}$. Other hydrometallurgical recovery processes resulting in $\mathrm{CoSO}_{4}$ or Co-oxalate require a two-step process to produce $\mathrm{LiCoO}_{2}$, involving the oxidation of cobalt sulfate and lithiation of cobalt oxide [20]. In contrast, our process is beneficial, as it produces $\mathrm{LiCoO}_{2}$ using a single-step reaction with $\mathrm{LiOH}$. This result demonstrates that $\mathrm{LiCoO}_{2}$ can be directly synthesized from the reaction of the precipitated Co-oxalate with $\mathrm{LiOH}$ without generating the by-product $\mathrm{Co}_{3} \mathrm{O}_{4}$, which would require an additional process to refine. To the best of our knowledge, this is the first demonstration of a single-step synthesis of $\mathrm{LiCoO}_{2}$ from Co-oxalate that is recycled by a hydrometallurgical process. We further investigate the effect of calcination temperature on the microstructure and morphology of the re-synthesized $\mathrm{LiCoO}_{2}$. SEM was used to observe the change in morphology of $\mathrm{LiCoO}_{2}$ with temperature. As shown in the SEM image (Figure 7a), the rod shape of $\mathrm{LiCoO}_{2}$ changed to a particular shape with increasing calcination temperature, suggesting dehydration and thermal decomposition of Co-oxalate during calcination. Furthermore, the resulting product shows a finer particle-like structure with increasing temperature due to densification of $\mathrm{LiCoO}_{2}$ in calcination. XRD results also support the assertion that the crystallinity of the re-synthesized $\mathrm{LiCoO}_{2}$ is enhanced with annealing temperature (Figure $7 \mathrm{~b}$ ). With increasing calcination temperature, the peak intensity also increases, and high-order peaks such as (009) and (105) appear, which are attributed to the enhanced crystallinity of $\mathrm{LiCoO}_{2}$. Note that the (104) peak intensity dramatically increases with temperature, indicating high crystallinity in the c-axis direction. The calculated degree of cation mixing with the ratio of the peak intensity (003) to (104) was 2.17 at $900{ }^{\circ} \mathrm{C}, 2.04$ at $700{ }^{\circ} \mathrm{C}$, and 1.85 at $400{ }^{\circ} \mathrm{C}$ [31-33]. It could be expected that $\mathrm{LiCoO}_{2}$ calcined at a high temperature of $900{ }^{\circ} \mathrm{C}$ will have good electrochemical properties, which will be discussed in the next section. The grain size analyzed based on the full width at half maximum (FWHM) of the (003) peak increased from $6.1 \mathrm{~nm}$ at $400{ }^{\circ} \mathrm{C}$ to $13.7 \mathrm{~nm}$ at $900^{\circ} \mathrm{C}$, which is in a good agreement with the enhanced crystallinity with high temperature calcination. We believe that calcination at high temperature induces growth along the (001) plane (which has the lowest surface energy) in order to minimize the surface energy, hence resulting in high crystallinity as well as a high degree of cation ordering [34,35].
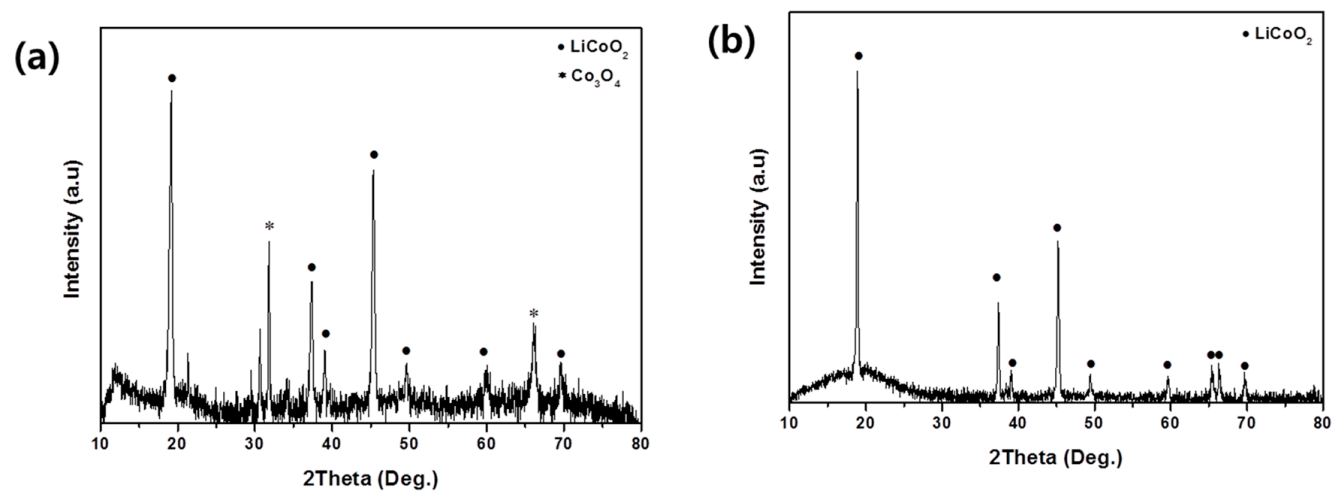

Figure 6. XRD spectrum of $\mathrm{LiCoO}_{2}$ produced from Co-oxalate by reaction with (a) $\mathrm{Li}_{2} \mathrm{CO}_{3}$ and (b) $\mathrm{LiOH}$. 

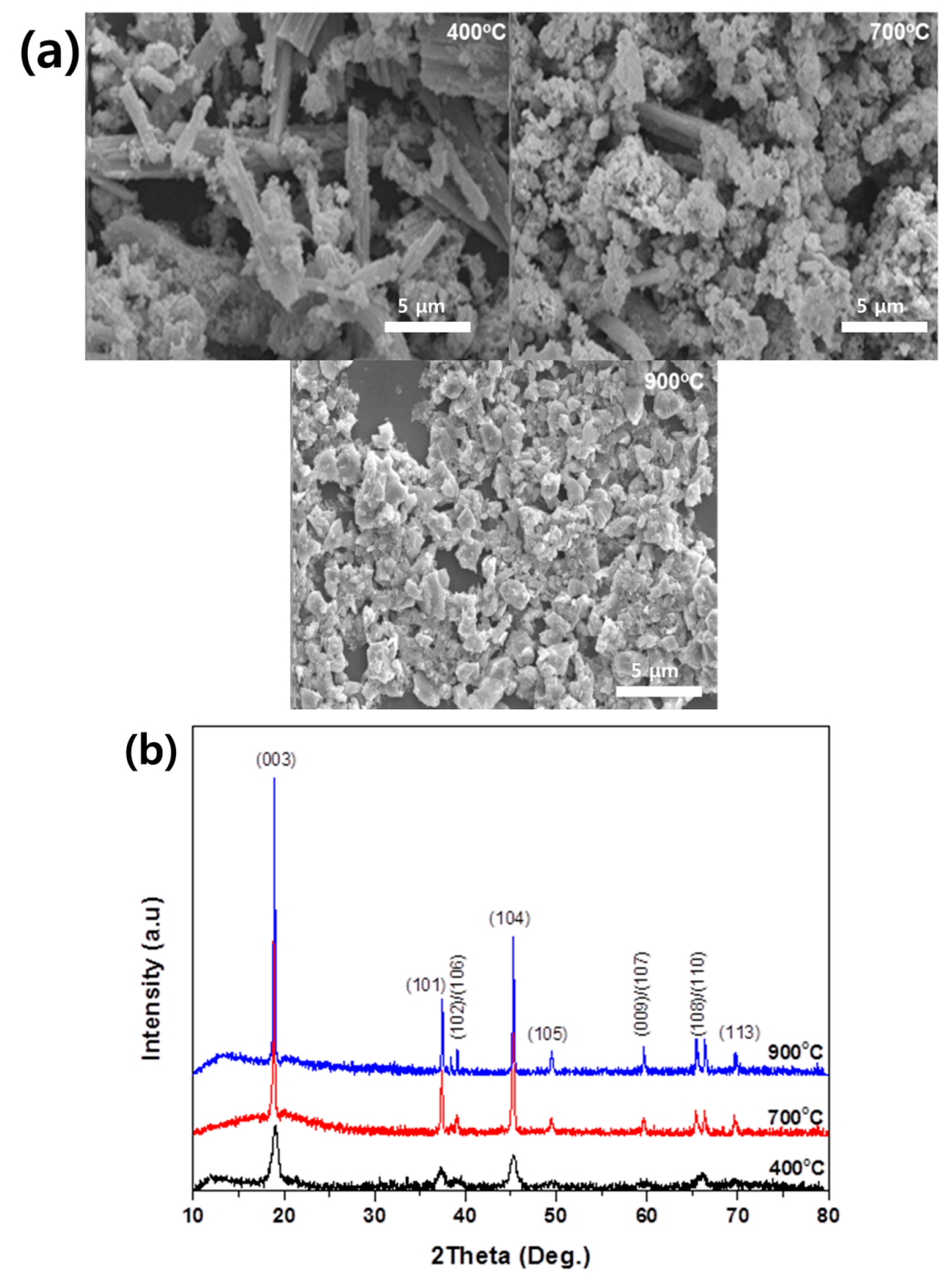

Figure 7. (a) SEM image and (b) XRD spectrum of $\mathrm{LiCoO}_{2}$ calcined at $400{ }^{\circ} \mathrm{C}, 700{ }^{\circ} \mathrm{C}$, and $900{ }^{\circ} \mathrm{C}$.

\subsection{Electrochemical Characterization}

The electrochemical properties of re-synthesized $\mathrm{LiCoO}_{2}$ calcined at high temperature were characterized using a cyclic voltammetry test. Figure 8 clearly shows that the peak for Li insertion occurs at $0.77 \mathrm{~V}$ and a desertion peak occurs at $0.53 \mathrm{~V}$, indicating that the electrochemical reaction occurs successfully in $\mathrm{LiCoO}_{2}$. However, in $\mathrm{LiCoO}_{2}$ calcined at $400{ }^{\circ} \mathrm{C}$, the Li-ion insertion peak appears at $0.51 \mathrm{~V}$, corresponding to the electrochemical reaction of arbitrary cobalt oxide, which can be referred to as $\mathrm{CoO}_{x}$, suggesting that calcination at low temperature can generate by-product cobalt oxide residue, as previously reported [28]. The discharge capacity was also measured by a half-cell test for samples calcined at $400{ }^{\circ} \mathrm{C}, 700{ }^{\circ} \mathrm{C}$, and $900{ }^{\circ} \mathrm{C}$ at a rate of $0.5 \mathrm{C}$ (Figure 9). The voltage profiles show that the discharge capacity was improved from $79.8 \mathrm{~mA} \cdot \mathrm{h} \cdot \mathrm{g}^{-1}$ in the sample calcined at $400{ }^{\circ} \mathrm{C}$ to $131 \mathrm{~mA} \cdot \mathrm{h} \cdot \mathrm{g}^{-1}$ in the one at $900{ }^{\circ} \mathrm{C}$ with increasing calcination temperature. This result is in good agreement with our $\mathrm{XRD}$ results, indicating that high temperature calcination induces a high degree of cation ordering [31,36]. It has been reported that the Li ion inserts more efficiently for a sample with a lower degree of cation ordering in a textured electrode structure thanks to a greater number of electrochemical active sites and a shorter diffusion length than a sample with a higher degree of cation ordering [30,35,37]. However, our electrodes were processed using powder in this study, and hence no preferential diffusion path of Li ions was introduced, in contrast to previous textured 
thin-film-based electrodes [38,39]. Furthermore, the re-synthesized $\mathrm{LiCoO}_{2}$ materials show very low values for the degree of cation ordering $(\sim 2)$, suggesting a short diffusion channel similar to a sample previously reported with a degree of cation ordering greater than four Therefore, it is expected that high impedance resulting from a high degree of crystallinity will have a more dominant effect on the electrochemical characteristics than the Li ion diffusion path $[33,40]$.

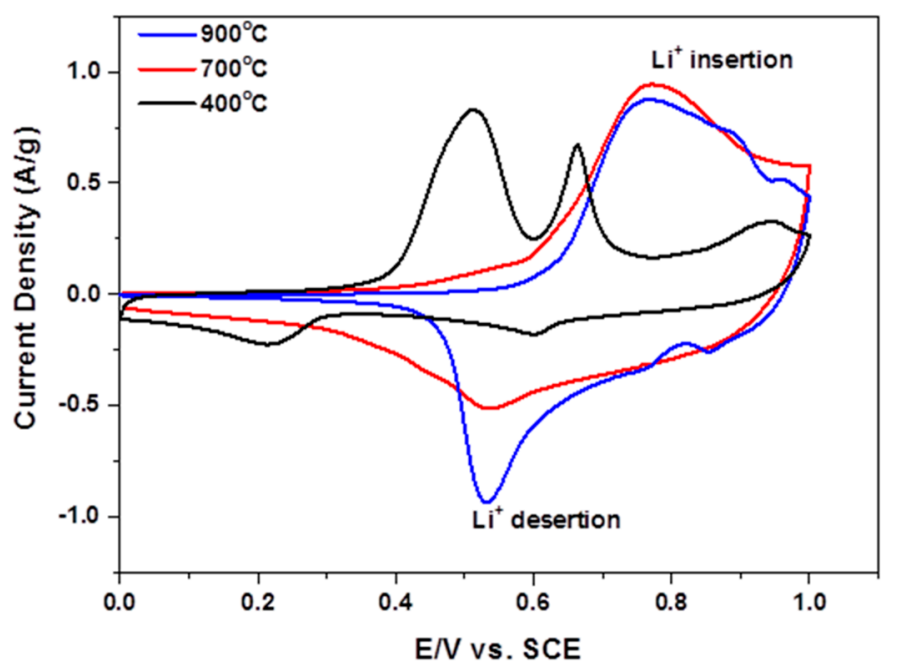

Figure 8. Cyclic voltammetry test of $\mathrm{LiCoO}_{2}$ calcined at $400{ }^{\circ} \mathrm{C}, 700{ }^{\circ} \mathrm{C}$, and $900{ }^{\circ} \mathrm{C}$. SCE: Saturated calomel electrode.
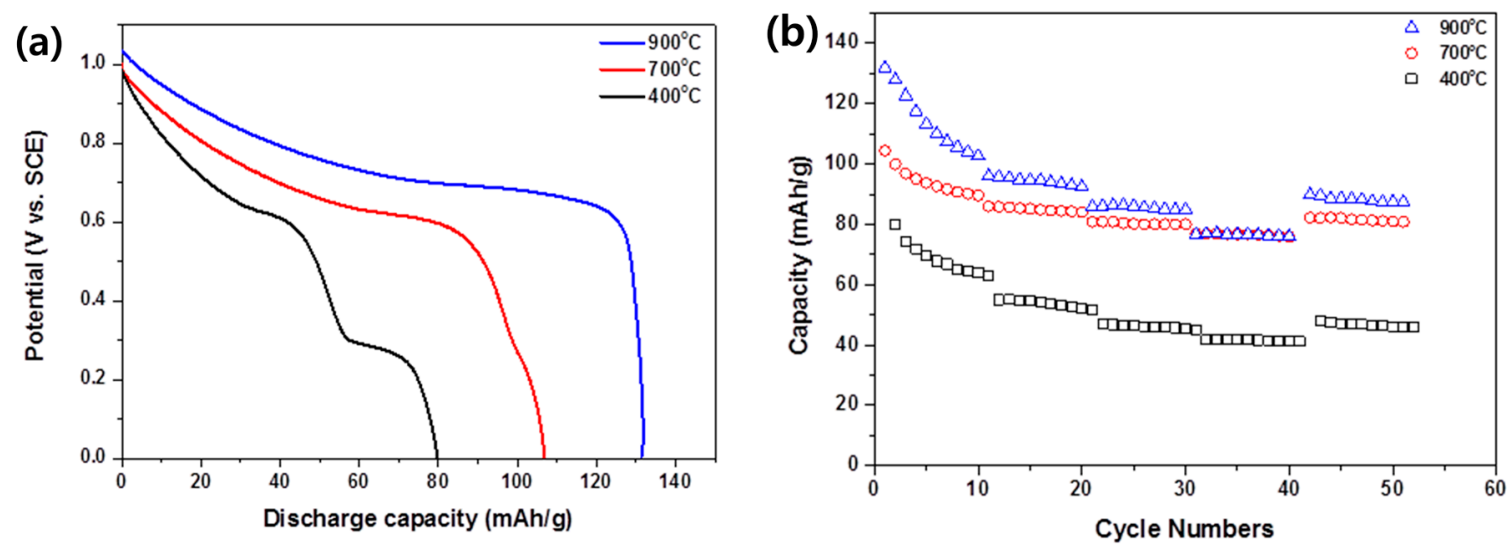

Figure 9. Half-cell test results for (a) discharge capacity and (b) rate capability.

Figure $9 \mathrm{~b}$ compares the rate capability up to a $10 \mathrm{C}$ rate for the samples calcined at $400{ }^{\circ} \mathrm{C}, 700{ }^{\circ} \mathrm{C}$, and $900{ }^{\circ} \mathrm{C}$. The $\mathrm{LiCoO}_{2}$ calcined at $900{ }^{\circ} \mathrm{C}$ exhibits a rate capability of $100 \mathrm{~mA} \cdot \mathrm{h} \cdot \mathrm{g}^{-1}$ at a rate of $1 \mathrm{C}$ and $82 \mathrm{~mA} \cdot \mathrm{h} \cdot \mathrm{g}^{-1}$ at a rate of $10 \mathrm{C}$. The discharge capacity of re-synthesized $\mathrm{LiCoO}_{2}$ initially decreases over a few cycles, which is expected due to some residue on the surface of $\mathrm{LiCoO}_{2}$ generated during our process, reacting with the electrolyte and resulting in a surface interface that increases the electrode impedance and induces poor power performance [41,42]. Improvement of the capacity retention via surface analysis and thorough element control will be further investigated in the near future.

\section{Conclusions}

In summary, a novel process to produce $\mathrm{LiCoO}_{2}$ from spent batteries has been developed using a one-pot process including both leaching and precipitation of Co to re-synthesize $\mathrm{LiCoO}_{2}$ through reaction with $\mathrm{LiOH}$. Co-oxalate can be used for re-synthesis of $\mathrm{LiCoO}_{2}$, and is obtained from spent 
batteries using malic acid as a leachant and oxalic acid as a precipitator. This process is shown to yield cobalt species with a high efficiency of $99.28 \%$ and achieve a process without the assistance of $\mathrm{H}_{2} \mathrm{O}_{2}$. We also find that an additional single-step reaction of $\mathrm{Co}$-oxalate with $\mathrm{LiOH}$ produces high-quality $\mathrm{LiCoO}_{2}$ without producing by-product cobalt oxide species; hence, an additional refinement process is not required. Our XRD and electrochemical characterization also suggest that the resulting $\mathrm{LiCoO}_{2}$ shows high crystallinity and good electrochemical properties as a cathode in LIBs, similar to the commonly-used $\mathrm{LiCoO}_{2}$. As a result, our novel process successfully demonstrated a complete recycling process of the cathode material of spent LIBs in a simple two-step process, which is composed of one-pot cobalt recovery and single step synthesis of $\mathrm{LiCoO}_{2}$. In addition, our recovery process is expected to potentially be environmentally friendly due to the removal of $\mathrm{H}_{2} \mathrm{O}_{2}$ in the recovery process. The environmental assessment of our process will be further investigated in a following report.

Acknowledgments: This work was financially supported by R\&D program of Korea Institute of Industrial Technology (KITECH). Hyun-Jong Kim is grateful to Mi-Yeon Kim of Dankook University for her helpful assistance and discussion.

Author Contributions: Hyun-Jong Kim and Hansung Kim conceived and designed the experiments; Young Min Park., Hana Lim and Ji-Hoon Moon performed the experiments; Young Min Park, Hyun-Jong Kim and Hansung Kim discussed and analyzed the data; Ho-Nyun Lee and Seong Ho Son contributed initial materials and analysis tools; Young Min Park and Hyun-Jong Kim wrote the paper.

Conflicts of Interest: The authors declare no conflict of interest.

\section{References}

1. Armand, M.; Tarascon, J.M. Building better batteries. Nature 2008, 451, 652-657. [CrossRef] [PubMed]

2. Goodenough, J.B.; Kim, Y. Challenges for rechargeable Li batteries. Chem. Mater. 2010, 22, 587-603. [CrossRef]

3. Tarascon, J.M.; Armand, M. Issues and challenges facing rechargeable lithium batteries. Nature 2001, 414, 359-367. [CrossRef] [PubMed]

4. Van Vliet, O.; Brouwer, A.S.; Kuramochi, T.; van den Broek, M.; Faaij, A. Energy use, cost and $\mathrm{CO}_{2}$ emissions of electric cars. J. Power Sources 2011, 196, 2298-2310. [CrossRef]

5. Kang, K.; Meng, Y.S.; Bréger, J.; Grey, C.P.; Ceder, G. Electrodes with high power and high capacity for rechargeable lithium batteries. Science 2006, 311, 977-980. [CrossRef] [PubMed]

6. Wang, X.; Gaustad, G.; Babbitt, C.W.; Richa, K. Economies of scale for future lithium-ion battery recycling infrastructure. Resour. Conserv. Recycl. 2014, 83, 53-62. [CrossRef]

7. Chen, X.; Xu, B.; Zhou, T.; Liu, D.; Hu, H.; Fan, S. Separation and recovery of metal values from leaching liquor of mixed-type of spent lithium-ion batteries. Sep. Purif. Technol. 2015, 144, 197-205. [CrossRef]

8. Ra, D.; Han, K. Used lithium ion rechargeable battery recycling using Etoile-Rebatt technology. J. Power Sources 2006, 163, 284-288. [CrossRef]

9. Nan, J.; Han, D.; Zuo, X. Recovery of metal values from spent lithium-ion batteries with chemical deposition and solvent extraction. J. Power Sources 2005, 152, 278-284. [CrossRef]

10. Kang, J.; Senanayake, G.; Sohn, J.; Shin, S.M. Recovery of cobalt sulfate from spent lithium ion batteries by reductive leaching and solvent extraction with Cyanex 272. Hydrometallurgy 2010, 100, 168-171. [CrossRef]

11. Chagnes, A.; Pospiech, B. A brief review on hydrometallurgical technologies for recycling spent lithium-ion batteries. J. Chem. Technol. Biotechnol. 2013, 88, 1191-1199. [CrossRef]

12. Espinosa, D.C.R.; Bernardes, A.M.; Tenório, J.A.S. An overview on the current processes for the recycling of batteries. J. Power Sources 2004, 135, 311-319. [CrossRef]

13. Paulino, J.F.; Busnardo, N.G.; Afonso, J.C. Recovery of valuable elements from spent Li-batteries. J. Hazard. Mater. 2008, 150, 843-849. [CrossRef] [PubMed]

14. Mishra, D.; Kim, D.J.; Ralph, D.E.; Ahn, J.G.; Rhee, Y.H. Bioleaching of metals from spent lithium ion secondary batteries using Acidithiobacillus ferrooxidans. Waste Manag. 2008, 28, 333-338. [CrossRef] [PubMed]

15. Xin, B.; Zhang, D.; Zhang, X.; Xia, Y.; Wu, F.; Chen, S.; Li, L. Bioleaching mechanism of Co and Li from spent lithium-ion battery by the mixed culture of acidophilic sulfur-oxidizing and iron-oxidizing bacteria. Bioresour. Technol. 2009, 100, 6163-6169. [CrossRef] [PubMed] 
16. Lupi, C.; Pasquali, M.; Dell'Era, A. Nickel and cobalt recycling from lithium-ion batteries by electrochemical processes. Waste Manag. 2005, 25, 215-220. [CrossRef] [PubMed]

17. Freitas, M.; Celante, V.G.; Pietre, M.K. Electrochemical recovery of cobalt and copper from spent Li-ion batteries as multilayer deposits. J. Power Sources 2010, 195, 3309-3315. [CrossRef]

18. Garcia, E.M.; Santos, J.S.; Pereira, E.C.; Freitas, M. Electrodeposition of cobalt from spent Li-ion battery cathodes by the electrochemistry quartz crystal microbalance technique. J. Power Sources 2008, 185, 549-553. [CrossRef]

19. Li, L.; Zhai, L.; Zhang, X.; Lu, J.; Chen, R.; Wu, F.; Amine, K. Recovery of valuable metals from spent lithium-ion batteries by ultrasonic-assisted leaching process. J. Power Sources 2014, 262, 380-385. [CrossRef]

20. Kang, J.; Sohn, J.; Chang, H.; Senanayake, G.; Shin, S.M. Preparation of cobalt oxide from concentrated cathode material of spent lithium ion batteries by hydrometallurgical method. Adv. Powder Technol. 2010, 21, 175-179. [CrossRef]

21. Li, L.; Dunn, J.B.; Zhang, X.X.; Gaines, L.; Chen, R.J.; Wu, F.; Amine, K. Recovery of metals from spent lithium-ion batteries with organic acids as leaching reagents and environmental assessment. J. Power Sources 2013, 233, 180-189. [CrossRef]

22. Ferreira, D.A.; Prados, L.M.Z.; Majuste, D.; Mansur, M.B. Hydrometallurgical separation of aluminium, cobalt, copper and lithium from spent Li-ion batteries. J. Power Sources 2009, 187, 238-246. [CrossRef]

23. Li, L.; Ge, J.; Wu, F.; Chen, R.; Chen, S.; Wu, B. Recovery of cobalt and lithium from spent lithium ion batteries using organic citric acid as leachant. J. Hazard. Mater. 2010, 176, 288-293. [CrossRef] [PubMed]

24. Sun, L.; Qiu, K. Organic oxalate as leachant and precipitant for the recovery of valuable metals from spent lithium-ion batteries. Waste Manag. 2012, 32, 1575-1582. [CrossRef] [PubMed]

25. Lee, C.K.; Rhee, K.I. Preparation of $\mathrm{LiCoO}_{2}$ from spent lithium-ion batteries. J. Power Sources 2002, 109, 17-21. [CrossRef]

26. Tarasova, I.I.; Dudeney, A.W.L.; Pilurzu, S. Glass sand processing by oxalic acid leaching and photocatalytic effluent treatment. Miner. Eng. 2001, 14, 639-646. [CrossRef]

27. Wang, D.; Wang, Q.; Wang, T. Morphology-controllable synthesis of cobalt oxalates and their conversion to mesoporous $\mathrm{Co}_{3} \mathrm{O}_{4}$ nanostructures for application in supercapacitors. Inorg. Chem. 2011, 50, 6482-6492. [CrossRef] [PubMed]

28. Ang, W.A.; Cheah, Y.L.; Wong, C.L.; Prasanth, R.; Hng, H.H.; Madhavi, S. Mesoporous cobalt oxalate nanostructures as high-performance anode materials for lithium-ion batteries: Ex-situ electrochemical mechanistic study. J. Phys. Chem. C 2013, 117, 16316-16325. [CrossRef]

29. Mizushima, K.; Jones, P.C.; Wiseman, P.J.; Goodenough, J.B. $\mathrm{Li}_{\mathrm{x}} \mathrm{CoO}_{2}(0<\mathrm{x}<-1)$ : A new cathode material for batteries of high energy density. Mater. Res. Bull. 1980, 15, 783-789.

30. Iriyama, Y.; Inaba, M.; Abe, T.; Ogumi, Z. Preparation of $c$-axis oriented thin films of $\mathrm{LiCoO}_{2}$ by pulsed laser deposition and their electrochemical properties. J. Power Sources 2001, 94, 175-182. [CrossRef]

31. Yoshio, M.; Tanaka, H.; Tominaga, K.; Noguchi, H. Synthesis of $\mathrm{LiCoO}_{2}$ from cobalt-Organic acid complexes and its electrode behaviour in a lithium secondary battery. J. Power Sources 1992, 40, 347-353. [CrossRef]

32. Tang, W.; Kanoh, H.; Ooi, K. Preparation of Lithium Cobalt Oxide by LiCl-Flux Method for Lithium Rechargeable Batteries. Electrochem. Solid State Lett. 1998, 1, 145-146. [CrossRef]

33. Zhang, H.; Baker, P.J.; Grant, P.S. Fabrication and electrical properties of bulk textured $\mathrm{LiCoO}_{2}$. J. Am. Ceram. Soc. 2010, 93, 1856-1859. [CrossRef]

34. Bates, J.B.; Dudney, N.J.; Neudecker, B.J.; Hart, F.X.; Jun, H.P.; Hackney, S.A. Preferred orientation of polycrystalline $\mathrm{LiCoO}_{2}$ films. J. Electrochem. Soc. 2000, 147, 59-70. [CrossRef]

35. Yoon, Y.; Park, C.; Kim, J.; Shin, D. Lattice orientation control of lithium cobalt oxide cathode film for all-solid-state thin film batteries. J. Power Sources 2013, 226, 186-190. [CrossRef]

36. Wang, B.; Bates, J.B.; Hart, F.X.; Sales, B.C.; Zuhr, R.A.; Robertson, J.D. Characterization of thin-film rechargeable lithium batteries with lithium cobalt oxide cathodes. J. Electrochem. Soc. 1996, 143, 3203-3213. [CrossRef]

37. Gao, S.; Wei, W.; Ma, M.; Qi, J.; Yang, J.; Zhang, J.; Guo, L. Sol-gel synthesis and electrochemical properties of $c$-axis oriented $\mathrm{LiCoO}_{2}$ for lithium-ion batteries. RSC Adv. 2015, 5, 51483-51488. [CrossRef]

38. Bruce, P.G.; Scrosati, B.; Tarascon, J.M. Nanomaterials for rechargeable lithium batteries. Angew. Chem. Int. Ed. 2008, 47, 2930-2946. [CrossRef] [PubMed] 
39. Zhang, H.J.; Wong, C.C.; Wang, Y. Crystal engineering of nanomaterials to widen the lithium ion rocking "Express Way": A case in $\mathrm{LiCoO}_{2}$. Cryst. Growth Des. 2012, 12, 5629-5634. [CrossRef]

40. Mizuno, Y.; Hosono, E.; Saito, T.; Okubo, M.; Nishio-Hamane, D.; Oh-ishi, K.; Kudo, T.; Zhou, H. Electrospinning synthesis of wire-structured $\mathrm{LiCoO}_{2}$ for electrode materials of high-power Li-ion batteries. J. Phys. Chem. C 2012, 116, 10774-10780. [CrossRef]

41. Wu, B.; Ren, Y.; Mu, D.; Liu, X.; Yang, G.; Wu, F. Effect of lithium carbonate precipitates on the electrochemical cycling stability of $\mathrm{LiCoO}_{2}$ cathodes at a high voltage. RSC Adv. 2014, 4, 10196-10203. [CrossRef]

42. Abraham, D.P.; Twesten, R.D.; Balasubramanian, M.; Petrov, I.; McBreen, J.; Amine, K. Surface changes on $\mathrm{LiNi}_{0.8} \mathrm{Co}_{0.2} \mathrm{O}_{2}$ particles during testing of high-power lithium-ion cells. Electrochem. Commun. 2002, 4, 620-625. [CrossRef]

(C) 2017 by the authors. Licensee MDPI, Basel, Switzerland. This article is an open access article distributed under the terms and conditions of the Creative Commons Attribution (CC BY) license (http:/ / creativecommons.org/licenses/by/4.0/). 